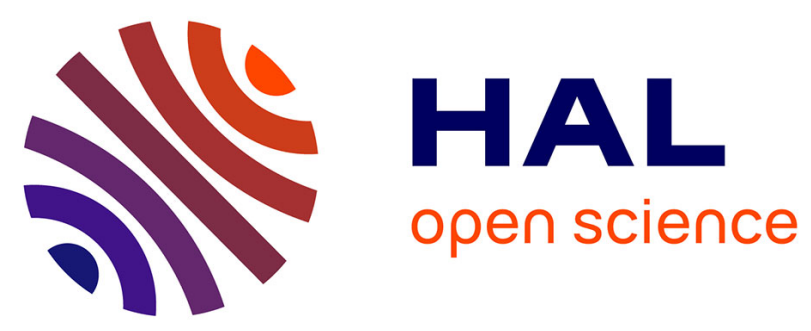

\title{
An innovative anodic approach for efficient immobilization of an acetylenic triple bond via silicon-carbon bond scission
}

\author{
V. Jouikov, J. Simonet
}

\section{- To cite this version:}

V. Jouikov, J. Simonet. An innovative anodic approach for efficient immobilization of an acetylenic triple bond via silicon-carbon bond scission. Electrochemistry Communications, 2018, 93, pp.49-52. 10.1016/j.elecom.2018.06.004 . hal-01835021

HAL Id: hal-01835021

https://hal-univ-rennes1.archives-ouvertes.fr/hal-01835021

Submitted on 13 Jul 2018

HAL is a multi-disciplinary open access archive for the deposit and dissemination of scientific research documents, whether they are published or not. The documents may come from teaching and research institutions in France or abroad, or from public or private research centers.
L'archive ouverte pluridisciplinaire HAL, est destinée au dépôt et à la diffusion de documents scientifiques de niveau recherche, publiés ou non, émanant des établissements d'enseignement et de recherche français ou étrangers, des laboratoires publics ou privés. 


\title{
An innovative anodic approach for efficient immobilization of an acetylenic triple bond via silicon-carbon bond scission
}

\author{
Viatcheslav Jouikov ${ }^{* a}$ and Jacques Simonet ${ }^{*}$ \\ ${ }^{a}$ UMR 6226 ISCR, CORINT, Unversité de Rennes 1, France \\ ${ }^{b}$ UMR 6226 ISCR, Unversité de Rennes 1, France
}

\begin{abstract}
The anodic scission of silicon-carbon bonds is successfully applied for the efficient covalent coverage of conducting solid surfaces with propynyl groups under quite simple conditions. The anodic cleavage of propynyl trimethylsilanes $(\mathrm{Me})_{3} \mathrm{Si}-\mathrm{C} \equiv \mathrm{C}-\mathrm{CH}_{2} \mathrm{R}$ in acetonitrile containing tetraalkylammonium salts leads to a dense grafting of the propyne $\mathrm{C} \equiv \mathrm{C}-\mathrm{CH}_{2} \mathrm{R}$ units onto glassy carbon, gold, and platinum surfaces. When R is a good leaving group (e.g. bromide), versatile electrodes might be prepared upon their polarization alternately (i) anodically and (ii) cathodically. A first example in which the anodic acetylation is immediately followed by cathodic immobilization of graphene and fullerene is reported.
\end{abstract}

Key words: Si-C bond; propynyl; anodic cleavage of organosilanes; grafting to gold; paired anodic/cathodic grafting.

\section{Introduction}

Glassy carbon is still considered as an efficient electrode material within the cathodic domain [1,2]. At the same time, most of the processes of fixation of organic moieties at the GC interface have been reported to occur through the addition of electrogenerated free radicals, mainly within the cathodic range [3-5]. Additionally, grafting processes with the radicals generated from the oxidation of alcohols [6], amines [7], and carboxylates [8] have been reported. On the other hand, the intrinsic cathodic charge of various carbon materials gives them a polynucleophlic character [9-11], making possible many efficient grafting processes reviewed recently [12].

The fact that different forms of carbon can be anodically charged in the presence of suitable reactive anions $[13,14]$ has been much less exploited. For instance, graphite can efficiently incorporate bromine in a manner obviously similar to the insertion of $\mathrm{Br}^{-}$into

\footnotetext{
*Corresponding author. E-mail: vjouikov@univ-rennes1.fr, tel: +33 22-323-6293.
} 
anodically charged carbon [13]. From this work emerges the idea of anodic generation of electrophilic centers at the carbon surface. Indeed, the capability of a wide variety of carbons (e.g. glassy carbon, graphites and fullerenes) to be anodically charged at potentials more positive than $+1.5 \mathrm{~V}$ vs. $\mathrm{Ag} / \mathrm{AgCl} / \mathrm{KCl}_{\mathrm{sat}}$ enables the formation of electrophilic centers on their surface which, in the presence of trimethylsilyl (TMS) substituted derivatives R-TMS, opens up new possibilities for modifying carbonaceous interfaces. This concept was considered in a recent work [14] originally developed to enable allylation and benzylation of different carbon materials. This process stresses the elevated kinetic instability of silicenium cations, in particular $\mathrm{TMS}^{+}$, due to their extreme electrophilicity. Very efficient reactions of such species with a large variety of both $\pi$ - and $\sigma$-electron donors have been reported. The oxidative cleavage of C-Si bonds, enhanced by the excellent leaving-group ability of $\mathrm{TMS}^{+}$cations, is covered in several reviews (see e.g. [15]). Along the same lines, allyl and benzyl nitrates have been formed under oxidative conditions from allyl and benzyl trimethylsilanes [16].

Recent work by Geiger $[17,18]$ underlined the interest in solid electrodes that can trap chemical functions via terminal lithio-activated ethynyl derivatives, permitting one to immobilize $\mathrm{R}-\mathrm{C} \equiv \mathrm{C}$ - units onto gold and carbon surfaces. The present contribution focuses on a new activation process, simple to achieve, using the anodic reactivity of $\mathrm{Si}-\mathrm{C}$ bonds (with $\mathrm{TMS}^{+}$as a leaving group [19]), which is applied to the immobilization of propynyl groups on solid surfaces such as carbon and gold.

\section{Experimental}

The present contribution focuses on the oxidation of trimethylsilylated compounds TMS-R with the $\mathrm{R}$ substituent being 1-propyne (1), 3-bromo-1-propyne (2) and 4-iodophenyl-1-propyne (3). All products are commercially available from Alfa Aesar. Anhydrous polar solvents - acetonitrile (ACN) for oxidation and N,N-dimethylformamide (DMF) for cathodic processes - were used to prepare $0.1 \mathrm{M}$ solutions of electrochemical grade tetramethylammonium and tetrabutylammonium salts (essentially with $\mathrm{BF}_{4}{ }^{-}, \mathrm{ClO}_{4}{ }^{-}$and $\mathrm{PF}_{6}^{-}$ anions). Fullerene $\mathrm{C}_{60}$ (> $99.0 \%$ purity) was purchased from TGI. Graphene was obtained in the laboratory by cathodic exfoliation of natural graphite [13].

In this first contribution on the use of ethynylic TMS derivatives for the efficient decoration of solid electrodes, only smooth glassy carbon and gold surfaces $\left(0.8 \mathrm{~mm}^{2}\right)$ are described. The electrodes were polished with silicon carbide paper (Struers 500 and 1200) and consecutively rinsed with water, ethyl alcohol and acetone.

All potentials are referred to $\mathrm{Ag} / \mathrm{AgCl} / \mathrm{KCl}_{\text {sat }}$ system in water. 


\section{Results}

\subsection{Anodic scission at gold and carbon}

It is established hereafter that organotrimethylsilanes incorporating the TMSsubstituted ethynyl unit are anodically oxidizable at GC and gold in acetonitrile containing $\mathrm{TMABF}_{4}\left(\mathrm{Scheme}_{1 \mathrm{~A}}\right)$. This process leads to the immobilization of 1-propynyl groups on gold to produce a very stable and compact surface coverage as shown by a sharp first peak (Figure $1 \mathrm{~B}, \mathrm{E}_{\mathrm{p}}=+1.54 \mathrm{~V}$ ) while the second scan does not exhibit any noticeable oxidation step. FTIR spectra of the propynyl-modified interfaces obtained in this way are shown in Figure 2. A rough estimation of the coverage based on current integration during the first scan leads to a global radical production of $(10 \pm 5) \times 10^{-9} \mathrm{~mol} \mathrm{~cm}^{-2}$ that could be associated with partial immobilization of the propynyl radical on gold, resulting in strong inhibition of its surface. This large amount does not exclude partial addition of transient radicals onto the primarily grafted unsaturated organic layer. By contrast, the oxidation of $\mathbf{1}$ at a carbon electrode was found to occur through a diffusion-controlled process, since the oxidation peak remains proportional to both the substrate concentration and the square root of the scan rate. The large difference in behaviour between gold and glassy carbon as anode materials could be explained by the catalytic effect of gold producing a large number of free radicals at the surface.

Grafting of a carbon-carbon triple bond onto Au and carbon is supported by the fact that the added unsaturated layers chemically bind iodine and bromine. Cathodic reduction of the resulting diiodo form (observed at $-0.49 \mathrm{~V}$ exclusively during the first scan) attests to the efficiency of immobilization. EDS mapping of the surfaces modified by chemical addition of halogens shows a dense coverage of the carbon surface with iodine and bromine atoms. Additionally, Figure 1 ( $\mathrm{C}$ and E) shows the FTIR and EIS responses of the grafted layer supporting an efficient coverage of the anodes.

\subsection{Coupled reduction/oxidation processes of versatile $\mathrm{TMS}-\mathrm{C} \equiv \mathrm{C}-\mathrm{CH} \mathrm{H}_{2} \mathrm{X}$ series}

The second approach concerns the behaviour of ethynyl structures possessing two electroactive groups that can be activated at opposite polarizations of the working electrode (gold or GC). Especially in the case of $\mathbf{2}$, where $\mathrm{X}=\mathrm{Br}$ (Scheme $1 \mathrm{~A}$ ), the anodically formed layer contains a leaving group that may be activated by switching the potential to the cathodic range, thus allowing the formation of a dense, transient, grafted propargyl layer as shown in Scheme 1B. The latter can react in situ with radicalophiles deposited on the layer or present in the solution. The reactions with graphene and fullerene $\mathrm{C}_{60}$ are presented in Figure 3 (B1 and 
B2, respectively). With graphene deposited by strong pressure onto the modified layer, the reduction of the propargylic layer is then blocked and the cathodic response is observed at $1.8 \mathrm{~V}$, which corresponds to the activation potential of graphite. The second scan displays a much smaller reduction of graphene which is quite probably caused by its linkage to the radical layer. By contrast, the tight contact of $\mathrm{C}_{60}$ with the propargylic layer creates a different situation depicted in Figure 3, B2, with the appearance of the two first one-electron reduction steps of fullerene ( $\mathrm{a}$ and $\mathrm{b}$ ) during the first scan, and of an additional reduction peak (grey arrow) probably involving ET from the $\mathrm{C}_{60}$ dianion transient to the propargylic bromide with cleavage of the $\mathrm{C}-\mathrm{Br}$ bond. One may notice a large difference between the currents assigned to the fullerene between the first and second scans, which is quite certainly due to the immobilization of the reduced $\mathrm{C}_{60}$ onto the modified layer by a totally irreversible process.

By contrast, the anodic oxidation of the TMS-capped propargylic layer covalently attached to the Au surface by cathodic grafting described above (Scheme 1 C, D) was shown to be successful (Figure 3, A2) as evidenced by the symmetric anodic peak $(+1.54 \mathrm{~V})$ assigned to scission of the $\mathrm{Si}-\mathrm{C}$ bond, as shown in 3.1. It is thought that a fairly thick layer was formed after 3 cathodic scans (up to $-2 \mathrm{~V}$ ). Under these conditions, the total elimination of the TMS groups from the modified interface was achieved at $+1.54 \mathrm{~V}$ after several anodic scans. The nature of the resulting layer has not yet been assessed.

\subsection{Extension of this grafting mode using TMS group}

Quite importantly, the easy and selective grafting of the propynyl moiety described above can be extended to the immobilization of many non-oxidizable groups connected to the $\left\{-\mathrm{C} \equiv \mathrm{C}-\mathrm{CH}_{2}-\right\}$ motif. One such example is the oxidation of compound $\mathbf{3}$ at smooth glassy carbon, performed at $E_{1 / 2}(3)$. The surface obtained after repetitive scanning up to $2.2 \mathrm{~V}$ was found to contain iodine in the grafted layer. Cathodic voltammetry on the surface modified in this way shows an irreversible step $\left(E_{1 / 2}=-1.22 \mathrm{~V}\right)$ observed during the first scan only. Integration of this cathodic peak permitted us to estimate that the surface coverage with $\mathrm{Ph}-\mathrm{I}$ amounts to $(3 \pm 0.5) \times 10^{-9} \mathrm{~mol} \mathrm{~cm}{ }^{-2}$. Additionally, EDS mapping of this interface before the reduction confirms the presence of a large number of iodine atoms in the grafted layer.

\section{Conclusion}

Anodic electrochemistry of organotrimethylsilanes R-TMS either at carbon (exploiting its positive doping) or at gold (direct oxidation) surfaces may offer a wide palette of new possibilities for modifying solid interfaces. Due to the high versatility of TMS units as 
excellent cationic leaving groups at positively charged solid surfaces, the efficient anodic immobilization of the acetylenic triple bond should be emphasised. Additionally, using the same process, the grafting of activated propynyl moieties, eventually decorated with an efficient anionic leaving group, was revealed to be successful, allowing, through facile anodic/cathodic sequential processes, efficient and innovative decoration of gold, and has been applied to different forms of carbon as well. These preliminary results show that other metals like platinum, palladium and titanium seem to present similar properties. Therefore, the present contribution can be seen as an introduction to the further development of promising paired processes of double immobilization using an ambifunctional reagent to build layers out of electron-rich chains in tight contact between two conducting solid materials (e.g. carbon vs. carbon, or gold vs. carbon as explained above).

\section{References}

[1] H. Lund, In: Organic Electrochemistry, H. Lund, O. Hammerich (Eds.), M. M. Dekker, New York, Basel, 2001, 223.

[2] R.L. McCreery, Advanced carbon electrode materials for molecular electrochemistry, Chem. Rev. 108/7 (2008) 2646.

[3] J. Pinson, F. Podvorica, Attachment of organic layers to conductive or semiconductive surfaces by reduction of diazonium salts, Chem. Soc. Rev. 34 (2005) 429.

[4] F. I. Podvorica, In: Aryl Diazonium Salts, Ed. M. Chehini, Wiley-VCH, 2012. 255.

[5] D. Belanger, J. Pinson, Electrografting: a powerful method for surface modification, Chem. Soc. Rev. 40 (2011) 3995.

[6] H. Maeda, Y. Yamauchi, M. Hosoe, T.-X. Li, E. Kasamatsu, H. Ohmori, Direct covalent modification of glassy carbon surfaces with 1-alkanols by electrochemical oxidation, Chem. Pharm. Bull. 42 (1994) 1870.

[7] B. Barbier, J. Pinson, G. Desarmot, M. Sanchez, Electrochemical bonding of amines to carbon fiber surfaces toward improved carbon - epoxy composites, J. Electrochem. Soc. 137 (1990) 1757.

[8] C.P. Andrieux, F. Gonzalez, J.-M. Saveant, Derivatization of carbon surfaces by anodic oxidation of arylacetates. Electrochemical manipulation of the grafted films, $J$. Am. Chem. Soc. 119 (1997) 4292.

[9] J. Simonet, H. Lund, Electrochemical behaviour of graphite cathodes in the presence of tetraalkylammonium cations, J. Electroanal. Chem. 75/2 (1977) 719.

[10] V. Jouikov, J. Simonet, Doping of cathodically polarized glassy carbon by natural graphite. A simple procedure for overlaying different carbons with electrochemically modifiable graphene layers, Electrochim. Acta 172 (2015) 28.

[11] V. Jouikov, J. Simonet, Novel method for grafting alkyl chains onto glassy carbon. Application to the easy immobilization of ferrocene used as redox probe, Langmuir 28/1 (2012) 931.

[12] V. Jouikov, J. Simonet, Electrochemical conversion of glassy carbon into a polynucleophilic reactive material. Applications for carbon chemical functionalization. A mini review, Electrochem. Comm. 45 (2014) 32.

[13] J. Simonet, Electro-catalysis at chemically modified solid surfaces, Ed. G. J. Hutchings, World Scientific, NJ, 2017, 217.

[14] V. Jouikov, J. Simonet, Langmuir 29/18 (2013) 5556. 
[15] P.D. Lickiss, In: The Chemistry of Organic Silicon Compounds, Eds. Z. Rappoport, Y. Apeloig, John Wiley and Sons, Chichester, UK, 1998, V. 2, 575.

[16] M. Ochiai, E. Fujita, M. Arimoto, H. Yamaguchi, A new synthesis of allyl nitrates from allylmetal (group IVb) compounds and thallium (III) nitrate, Chem. Pharm. Bull. 32 (1984) 887.

[17] M.V. Sheridan, K. Lam, W.E. Geiger, An anodic method for covalent attachment of molecules to electrodes through an ethynyl linkage, J. Am. Chem. Soc. 135 (2013) 2939.

[18] M.V. Sheridan, K. Lam, W.E. Geiger, Covalent attachment of porphyrins and ferrocenes to electrode surfaces through direct anodic oxidation of terminal ethynyl groups, Angew. Chem. Int. Ed. 52 (2013) 12897.

[19] J.-I. Yoshida, T. Murata, S. Isoe, Oxidative cleavage of carbon-silicon bond in allylsilanes and benzylsilanes, Tetrahedron Lett. $27 / 29$ (1986) 3373. 


\section{Legends for Figures}

Figure 1. Anodic modification of solid surfaces with TMS-R compounds. (A) Propynation at gold through a radical process. (B) Anodic oxidation of TMS-propyne $\left(6 \mathrm{mmol} \mathrm{L}^{-1}\right)$ at a gold microelectrode $\left(0.8 \mathrm{~mm}^{2}\right)$ in $\mathrm{AN} / 0.1 \mathrm{M} \mathrm{TMABF}_{4}$. Two first scans. Scan rate $50 \mathrm{mV} \mathrm{s}^{-1}$. (C) FTIR spectrum of the layer obtained from the anodic oxidation of TMS-propyne 1 (12 mmol $\mathrm{L}^{-1}$ ) at $+1.54 \mathrm{~V}$ at smooth gold. (D) For comparison, FTIR response of Au surface before addition. (E) Nyquist plots of the reduction of chloranil $\left(3 \mathrm{mmol} \mathrm{L} \mathrm{L}^{-1}\right)$ in ACN/0.1 $\mathrm{mmol} \mathrm{L}^{-1}$ $\mathrm{TBAPF}_{6}$ at a smooth Au electrode with freshly immobilized propyne layer. (F) Same as in (E), at the non-modified surface. $E=-1.16 \mathrm{~V}, \Delta E=10 \mathrm{mV}$. Frequency range from $0.306 \mathrm{MHz}$ to $43 \mathrm{mHz}$.

Figure 2. FTIR spectra of GC interface: (A) bare, (B) GC with grafted $-\mathrm{C} \equiv \mathrm{CCH}_{2} \mathrm{Br}$, (C) GC with grafted $-\mathrm{CH}_{2} \mathrm{C} \equiv \mathrm{CMe}$. (D) $\mathrm{GC}$ with grafted $-\mathrm{CH}_{2} \mathrm{C} \equiv \mathrm{CTMS}$. (a) $2850-2960 \mathrm{~cm}^{-1}\left(v_{\mathrm{CH}_{3}}\right)$ and $2960-3000 \mathrm{~cm}^{-1}\left(v_{\mathrm{CH}_{2}}\right),\left(\right.$ b) $2180--2210 \mathrm{~cm}^{-1}\left(v_{\mathrm{C} \equiv \mathrm{C}}\right)$. (c) $1450,1380 \mathrm{~cm}^{-1}\left(\delta_{\mathrm{CH}_{2}}, \mathrm{CH}_{3}\right)$ and $1410,1320 \mathrm{~cm}^{-1}\left(\delta_{\mathrm{C}-\mathrm{Si}}\right) .(d) 1150 \mathrm{~cm}^{-1}\left(\delta_{\mathrm{CH}_{2}-\mathrm{Br}}\right)$.

Figure 3. Principle of a double cleavage/immobilization at smooth gold with a typical TMSRX compound: reduction step (A1) followed by oxidation (A2) of the primarily grafted layer. After its sonication and rinsing, cathodic reduction of an acceptor (or any radicalophile) deposited at the modified interface can be performed. (A1) Three consecutive scans of the reduction of TMS-C $\equiv \mathrm{C}-\mathrm{CH}_{2} \mathrm{Br}\left(13 \mathrm{mmol} \mathrm{L}^{-1}\right.$ in $\left.\mathrm{DMF} / 0.1 \mathrm{M} \mathrm{TMABF}_{4}\right)$ at a smooth gold electrode $\left(0.8 \mathrm{~mm}^{2}\right)$. Scan rate $50 \mathrm{mV} \mathrm{s}^{-1}$. (A2) The immobilized TMS-C $\equiv \mathrm{C}_{-} \mathrm{CH}_{2}$ - layer is now anodized in $\mathrm{ACN} / \mathrm{TMABF}_{4}$. The anodic signal assigned to oxidation of the TMS-carbon bond progressively vanishes upon scanning. (B1), (B2) The electrodes prepared according to A1 are covered and rubbed with $\mathrm{C}_{60}$ or graphene and cathodically reduced in DMF leading to an external addition of radicalophilic particles. See text.

Scheme 1. TMS-C $\equiv \mathrm{C}-\mathrm{CH}_{2} \mathrm{X}$ as a versatile ambifunctional grafting agent. 


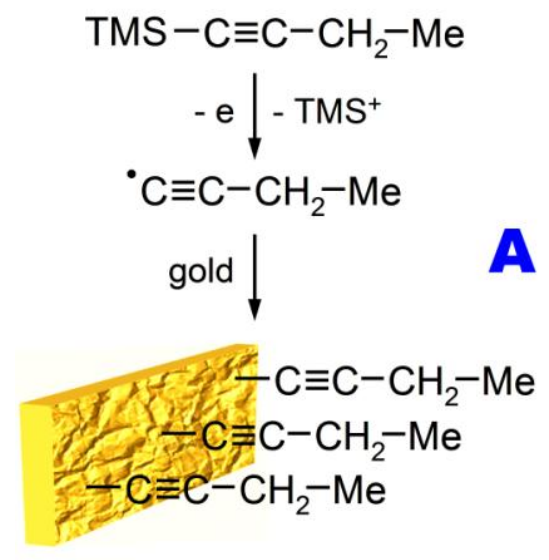

Anodic grafting to gold
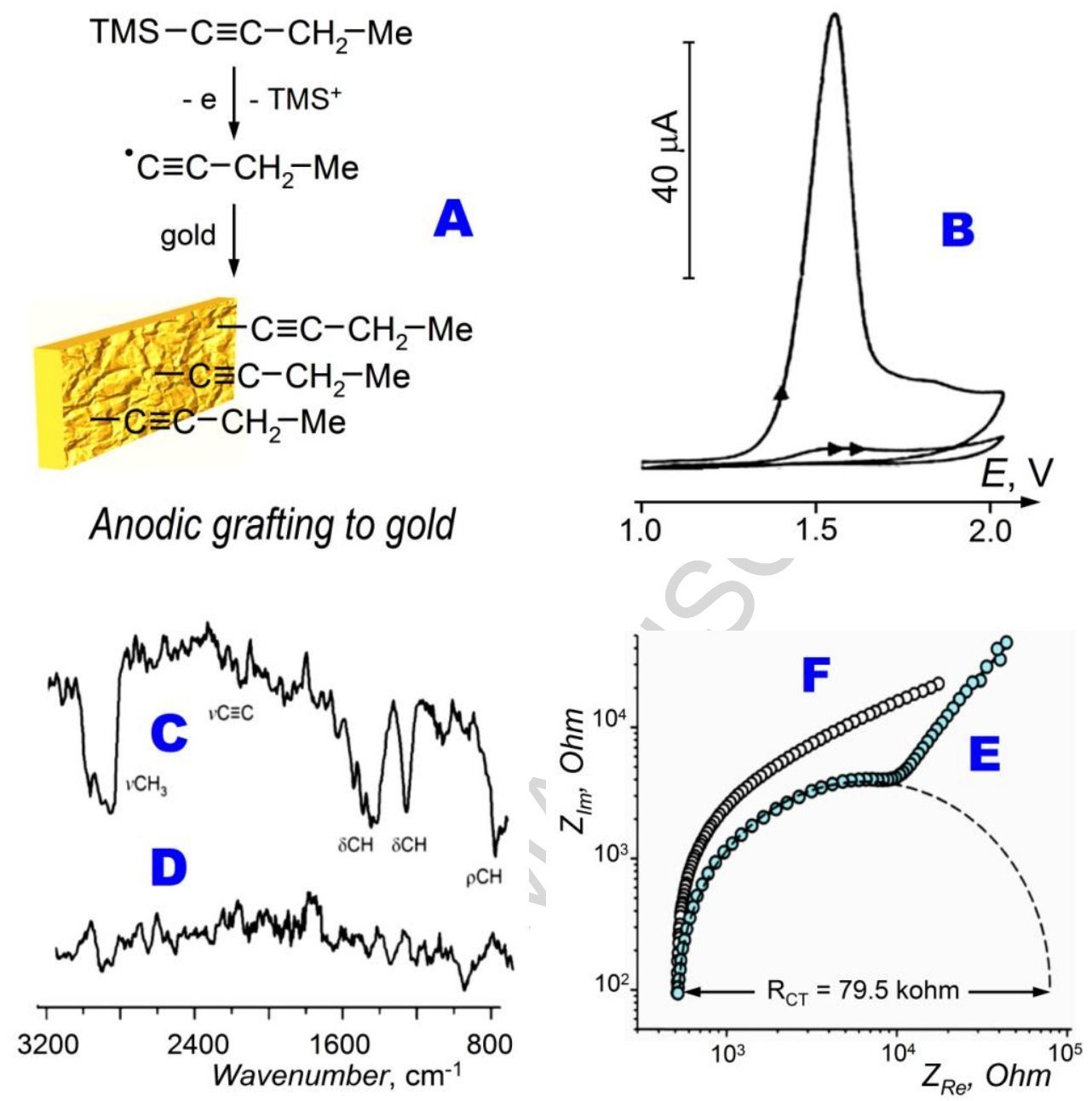

Figure 1 


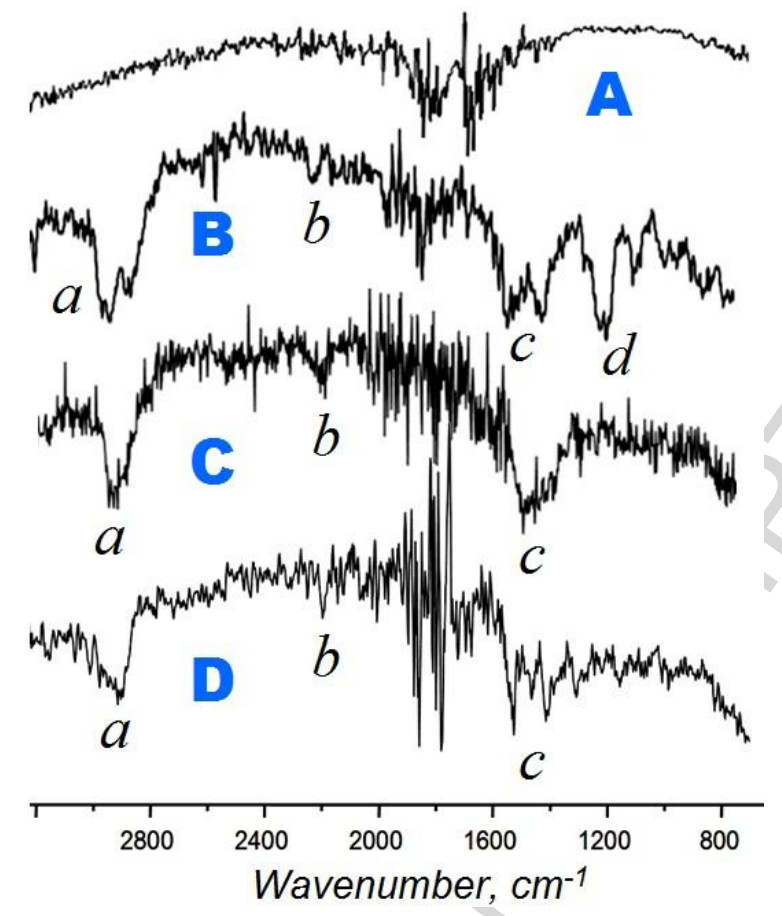

Figure 2 

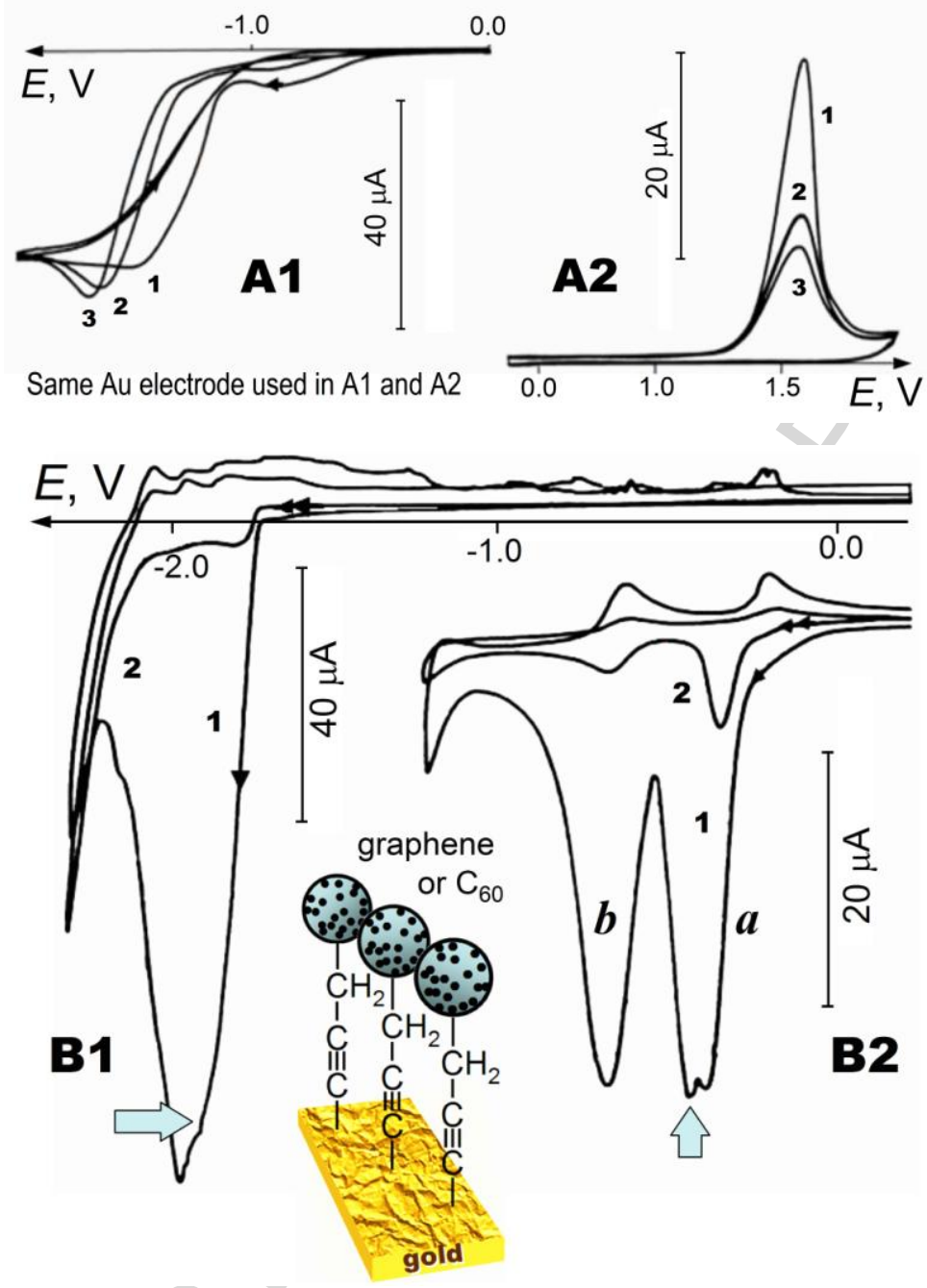

Figure 3 


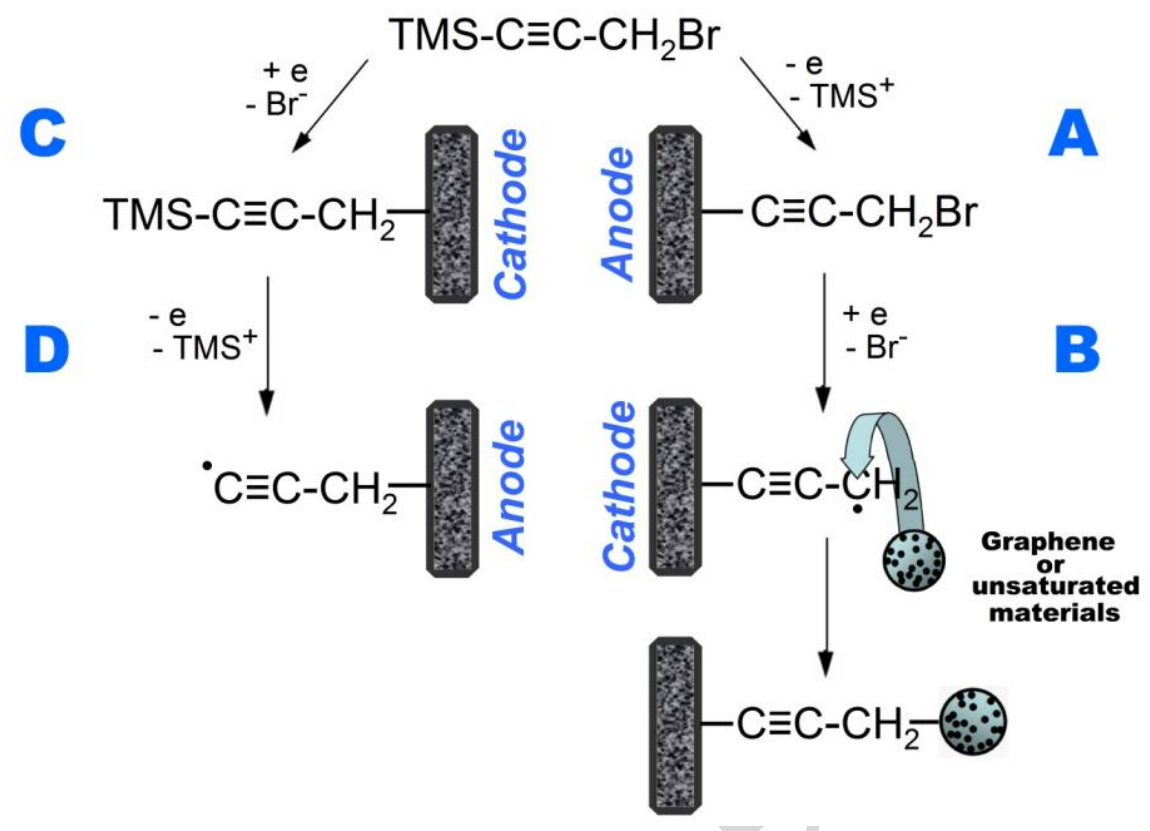

Scheme 1

GC 
Graphical abstract

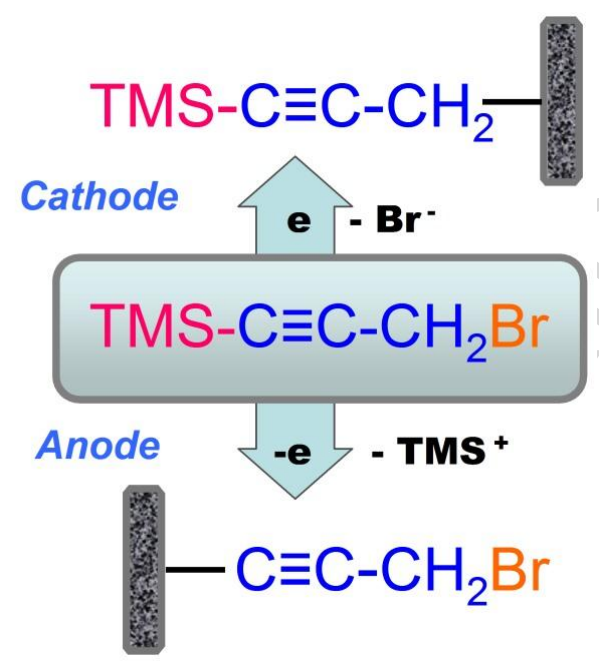




\section{Highlights}

- The anodic scission of silicon-carbon bonds was successfully realized at solid interfaces at potentials above $+1.5 \mathrm{~V}$ vs. $\mathrm{Ag} / \mathrm{AgCl}$ electrode.

- The propynyl moiety was covalently immobilized onto gold, platinum and glassy carbon surfaces.

- With gold, particularly dense and compact coverages were obtained.

- This new method of direct grafting of ethynyl groups to solid surfaces is easy and requires simple conditions (acetonitrile tetraalkylammonium salts). 